\title{
PERO ¿HUBO GUERRA EN TONINÁ? O DE CÓMO LAS APARIENCIAS ENGAÑAN
}

\section{Maricela Ayala Falcón}

Centro de Estudios Mayas. Instituto de Investigaciones Filológicas Universidad Nacional Autónoma de México

\begin{abstract}
The purpose of this paper is to present the epigraphic and archaeological information that we have about war in Toniná, a Classic Maya city. The advancements overwhelmed in the deciphering of Maya writing open a new corpus of information about Maya culture. Since the publication of $A$ Forest of Kings (Schele and Freidel), many scholars have dedicated their efforts to recover by this means the Prehispanic history of this group, sometimes with success.

I am presenting here a case in which the evidence does not seem to correspond, in some ways, to Classic Maya tradition. At the same time, it contributes with new data to the recovery of the historical past at the region.
\end{abstract}

RESUMEN: El propósito de este artículo es presentar la información epigráfica y arqueológica que tenemos sobre Toniná, una ciudad del Clásico maya. Los avances logrados en el desciframiento de la escritura maya han abierto un nuevo campo de información para esta cultura. Desde la publicación de $A$ Forest of Kings (Schele y Freidel), muchos investigadores han dedicado sus esfuerzos a la recuperación de la historia prehispánica de los mayas bajo tales enfoques, algunas veces con éxito.

En este artículo se presenta un caso en el cual las evidencias no parecen corresponder, en ocasiones, con la tradición maya clásica. En él también se contribuye con nueva información a la recuperación del pasado histórico de la región.

Los conceptos acerca de la guerra en el área maya durante la época prehispánica han variado de un extremo a otro. Desde aquella imagen defendida por Eric Thompson de los mayas presentados como una etnia dedicada al saber filosófico, el estudio del tiempo y la astronomía, todo ella de acuerdo con la bella idea del "noble salvaje" (nacida en el siglo XVII), defendida a priori a pesar de las evidencias de la misma iconografia en las imágenes prehispánicas y la información en los textos coloniales, hasta un extremo opuesto según el cual (I. J. Gelb; 1963) eran unos salvajes sin cultura dedicados a guerrear constantemente entre sí o contra los pueblos vecinos, ninguna de las dos afirmaciones es to- talmente verdadera o falsa, $y$ es que no se debe generalizar sin bases.

Tomemos como ejemplo el planteamiento de Eric Thompson en su obra Grandeza y decadencia de los mayas (cap. III; 1959), donde culpaba a la "polilla mexicana" de haber sido la introductora - a la zona maya- de prácticas culturales como los sacrificios sangrientos y la guerra. $\mathrm{Y}$ es que el autor veía a los mayas con una visión idílica. Cabe señalar cómo, más o menos en la misma época, otro autor dedicado al estudio de las escrituras, I. J. Gelb, en su obra A Study of Writing (1963), se refería a ellos como un grupo de salvajes que andaban semidesnudos, desconocían el

Estudios de Cultura Maya. Vol. XXII, 2002

Instituto de Investigaciones Filológicas/

Centro de Estudios Mayas, UNAM 
arado, eran caníbales siempre en guerra y como consecuencia, incapaces de poseer una escritura. Seguramente ningún mayista de los de esa época leyó a Gelb. O quizá sí y le hicieron notar sus errores, porque en ediciones posteriores el autor omitió ese pasaje denigrante y peyorativo acerca de los mayas.

Sin embargo, la idea de Thompson sobre el maya como un noble indígena tuvo gran aceptación (siglo $\mathrm{xx})$, y continuó siendo considerado un grupo no hostil, a pesar de las evidencias. No olvidemos que el último grupo mesoamericano que se rindió a los españoles fueron los itzáes, y esto sucedió al finalizar el siglo XVII. Pero obviamente ello no significó nada para los nuevos invasores, los de los siglos XIX y XX con la United Fruit (Alfred P. Maudslay, 1889-1902) o la misma Carnegie Institution (inicios del siglo $\mathrm{xx}$ ), porque los levantamientos en la región habían empezado y continuado durante mucho tiempo: desde el principio de la dominación española hasta las llamadas "guerras de castas" llevadas a cabo por los mayas de la península yucateca y posteriormente por los tzotziles en Chiapas sin que por ello se afectara la posibilidad de conquista de la región.

Pero tanto las compañías europeas explotadoras de la zona durante el siglo XIX, como los arqueólogos norteamericanos o ingleses en el siglo $\mathrm{XX}$, decidieron trabajar el área maya puesto que estaba llena de múltiples frutos.

Es cierto que había otras evidencias bélicas desde la época prehispánica y éstas eran obvias, como ya fue dicho, y eran evidentes en los mismos monumentos esculpidos por los mayas clásicos, en los cuales podía observarse tanto a personajes armados en imagen única, como con individuos a los cuales tomaban por el cabello o estaban postrados a sus pies en actitud de sumisión. Pero Thompson, quizá protegiendo su imagen idílica del "noble indígena", que había sido desprotegido por la United Fruits y la Carnegie Institution, argumentó que los mayas no se ocupaban de la guerra ni de los sacrificios, y solamente pensaban en la milpa, en sus dioses y en el calendario.

Cuando Linda Schele y Mary Miller publicaron Blood of Kings (1986), su llamada de atención a la preEstudios de Cultura Maya. Vol. XXII, 2002

Instituto de Investigaciones Filológicas/

Centro de Estudios Mayas, UNAM

ISSN 0185-2574 sencia de la sangre en las inscripciones mayas - tema que fue el eje de su obra - causó un tremendo impacto a nivel mundial, especialmente en México, donde prácticamente fue rechazada por contradecir el concepto bajo el cual se veía a la cultura maya prehispánica y a los mayas modernos.

En 1990 se publicó A Forest of Kings de Linda Schele y David Freidel. Su obra se distinguió por ser una compilación de todos los trabajos y avances realizados sobre la escritura e iconografia maya en esos últimos años y en ella se retomó el problema de la guerra entre las ciudades mayas durante la época prehispánica, pero con evidencias más sólidas producto del desciframiento de su escritura jeroglífica.

El tema no era nuevo puesto que la misma Tatiana Proskouriakoff en sus obras clásicas sobre Piedras Negras (1960) y Yaxchilán (1963-1964), al probar el contenido histórico de las inscripciones había logrado identificar tanto los verbos para capturar y sacrificar, entre otros, como el cátucho para captor.

Con base en ello y en los estudios subsecuentes fue que les tocó a Schele y Freidel sintetizar las evidencias sobre el tema de la guerra. El error en su trabajo, a mi modo de ver, consistió en la generalización que hicieron acerca de algunos conceptos representados e identificados iconográfica y epigráficamente como asociados a la guerra en algunas ciudades, para toda el área maya.

Los mayistas empezaron a encontrar evidencias de dichas guerras prehispánicas, como había ocurrido anteriormente en el caso del sacrificio, pero si bien las evidencias observadas e identificadas estaban prerentes en algunos sitios, no lo están en todos y los datos y registros analizados posteriormente, como es el caso de Toniná, han hecho surgir dudas acerca de la generalización de tales planteamientos como explicaré a continuación.

\section{Y acerca de Toniná}

Este trabajo se refiere a las evidencias acerca de la guerra en Toniná, Chiapas, sitio cuyo nombre en la época prehispánica, tal como se registra en su Glifo Emblema, 
fue el de: Po'o-che y sus habitantes fueron los Po'o winikob, los del linaje del "Árbol Po’o, la Vía Láctea o la Gran Ceiba" (Smailus, 1975: 100-101; Ayala, 1995; 253-254).

Toniná fue calificado por Schele y Freidel como uno de los sitios con mayores evidencias de guerra por su iconografia, es decir, las evidencias de cautivos en monumentos. Efectivamente, Toniná sostuvo varios eventos bélicos, tal como lo atestiguan sus monumentos relativos a prisioneros, pero los datos argumentados por Schele y Freidel en su generalización acerca de la iconografia de guerra, como el traje de Tláloc y las armas que porta el gobernante, no se encuentran en Toniná. Aquí tanto Schele como Freidel cometieron el mismo error que cometió Marcus (1976) cuando quisieron generalizar, con base en sus conocimientos de ese momento, las evidencias de guerra en el área maya sin tomar en cuenta las diferencias.

$\mathrm{Y}$ es que Toniná tiene una forma distinta de ser y expresarse. El análisis y estudio de las evidencias acerca de la guerra en Toniná que he llevado a cabo, muestra una forma distinta de realización como puede comprobarse por sus contextos epigráfico e iconográfico, los cuales además se pueden comprobar por la arqueología e historia. Sus divergencias con las del resto del área maya conocida resultan tan importantes en relación a lo dicho por Schele y Freidel que, pienso, deben ser tomadas en cuenta en la reconstrucción histórica del área no solamente para el período prehispánico, sino también para el colonial e, inclusive, el moderno.

\section{De Toniná y su situación histórica}

Comencemos por la situación geográfica de Toniná como ciudad o centro ceremonial ubicado en la cima del Valle de Ocosingo, sitio de paso si se trata del cami- no emprendido para atravesar por tierra la región desde el Golfo de México a Guatemala, es decir, sin usar las vías lacustres, lugar poco accesible pues hay que cruzar la zona montańosa.

El desarrollo del sitio abarca desde el Preclásico hasta el Postclásico, teniendo su periodo de mayor auge en el Clásico tardío (593-904 d.C., cfr. Becquelin y Baudez, 1982-1984; vol. I). Sus inscripciones, en lugar de las consabidas estelas, se encuentran escritas sobre las espaldas de las representaciones de los mismos gobernantes: imágenes esculpidas en bulto completo $\mathrm{y}$ asentadas, mediante una espiga, sobre bases cuadrangulares donde se continúa el texto. Existen otras inscripciones en los llamados altares o "calendarios", textos en piedras de forma circular cuyo diámetro varía. Algunos tienen figuras al centro pero por lo regular muestran el glifo Ahaw correspondiente al final de período relevante en la inscripción. Se trata de monumentos para conmemorar finales de período importantes para el gobernante autor del altar.

Dado que las inscripciones no están en "estelas" los estudiosos llamaron desde un principio monumentos ${ }^{2}$ a todos estos objetos; a la fecha se conocen 140 numerados por la $\mathrm{MAEF}^{3} \mathrm{y}$ varios sin numerar.

El primer estudio llevado a cabo en Toniná, valiéndose para ello de la nueva epigrafía, lo realizó Peter Mathews, quien identificó al posible Glifo Emblema del sitio, a ocho gobernantes y varios personajes. Por $\mathrm{mi}$ parte, apoyándome en el trabajo de Mathews y en los nuevos monumentos descubiertos, corregí dicha lista, el Glifo Emblema del lugar e identifiqué el nombre del sitio (ver nota 1) Los gobernantes siguen siendo ocho, pero hubo varios cambios en los nombres y fechas.

Toniná nos muestra ciertas diferencias en las manifestaciones escritas con las del resto de los grupos mayas del área Clásica y para explicar tales diferencias me avocaré a la llamada iconografía de guerra.

' El Glifo Emblema de Toniná, por su construcción glífica y función antropológica, se debió leer , en mi opinión: Ah Po K'u K'ik' po'o, es decir: "Sagrado Señor del trono del linaje, [de] el árbol sagrado...." (Ayala, s.f.).

${ }^{2}$ La primera catalogación de los Monumentos de Toniná se debe a Blom y LaFarge (1926-1927).

${ }^{3}$ Misión Arqueológica y Etnográfica Francesa; MAEF, antes MAF: Misión Arqueológica Francesa.

Estudios de Cultura Maya. Vol. XXII, 2002

Instituto de Investigaciones Filológicas/

Centro de Estudios Mayas, UNAM

ISSN 0185-2574 
Existen dos elementos iconográficos reconocidos para identificar las escenas de batalla: personajes armados y cautivos. Ambos se encuentran en parte de los monumentos esculpidos y pintados del área maya: un personaje encima de otro, un personaje en postura de sumisión frente a otro, un personaje que toma por el cabello a otro. Toda esta iconografía ya era conocida desde el trabajo de Proskouriakoff, pero a ella se agregó, por Claude Baudez y Peter Mathews (1978: 3140), la presencia de cuerdas en los brazos de los cautivos como indicador de tal condición. Posteriormente Schele y Freidel, al hablar de las escenas de triunfo, añadieron el llamado traje de Tláloc que se empezó a usar, según los autores, a raíz del triunfo de Tikal sobre Uaxactún y que se caracteriza porque el gobernante está vestido como guerrero, portando un atuendo típico y con armas correspondientes a dicha actividad bélica: escudos, lanzas, cuchillos y en algunos casos muy tempranos, lanzadardos o $\mathrm{kul}$, en maya yucateco.

En Toniná no hay, en los monumentos descubiertos hasta el momento, representaciones de gobernantes armados o vistiendo el traje de Tláloc (fig. 3). Ello no significa que los dirigentes del sitio hubieran perdido todas las batallas. Por el contrario, hay evidencias de que esta ciudad nunca perdió una batalla. Sin embargo, como ya mencioné, no acostumbraban usar dicho atuendo para festejar su triunfo, aunque sí pelearon en diversas ocasiones, saliendo vencedores en todas ellas.

Se conoce una gran cantidad de esculturas de prisioneros en Toniná, y de hecho fue la presencia de esos monumentos la que llevó a los mayistas a pensar en el sitio como una ciudad profundamente guerrera, pero las evidencias que he podido obtener al analizar a los prisoneros muestran diferencias de interés.

Es verdad que en Toniná hay gran cantidad de imágenes de cautivos, pero aquí, a diferencia de otros sitios, en lugar de despojarlos de todo su atuendo se les permitió conservar algún elemento identificador de estatus social, siendo el más importante (para mi tra-

Estudios de Cultura Maya. Vol. XXII, 2002

Instituto de Investigaciones Filológicas/

Centro de Estudios Mayas, UNAM

ISSN 0185-2574

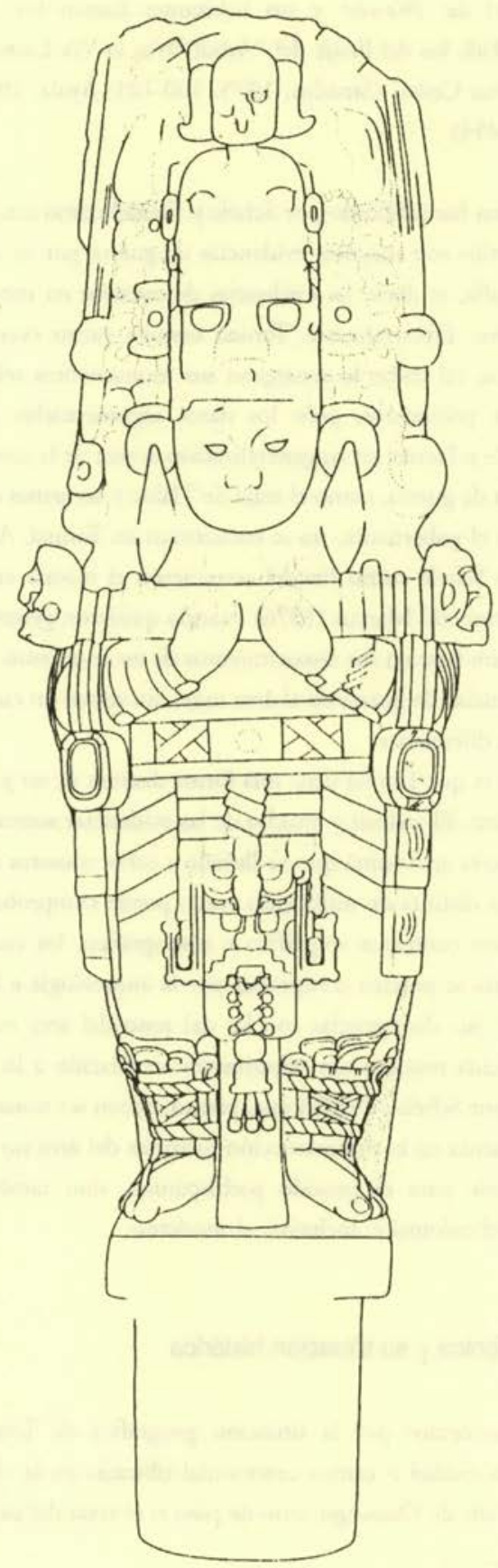

Fig. 1. Representación tipica de un gobernante de Toniná. Monumento 26 (dibujo de Mathews, 1983). 

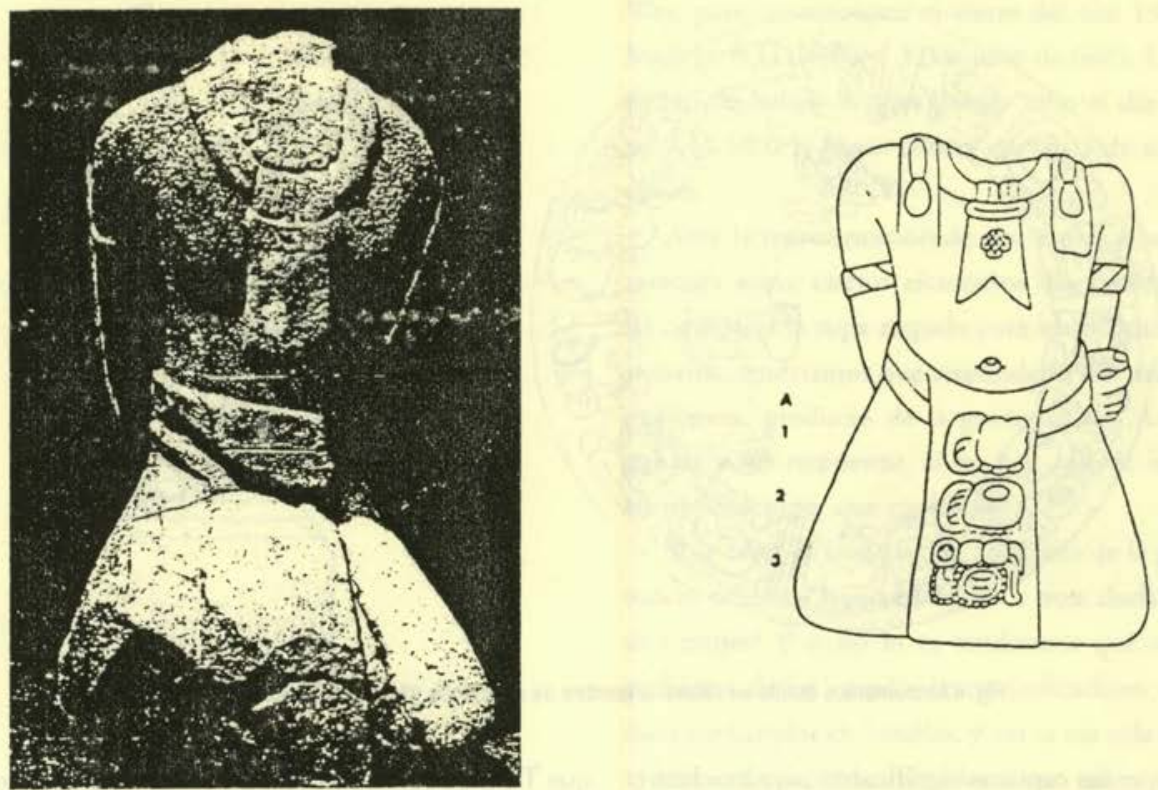

Fig. 2. El mismo prisionero en diferentes monumentos (dibujo de Mathews).

bajo) el collar porque ha sido a través de él como he podido identificar a los cautivos; en ocasiones también llevan su nombre glífico escrito sobre el cuerpo o en el braguero, además de estar en la inscripción asociada (fig. 2), con lo cual se viene a corroborar si la identificación propuesta es correcta. Sólo en un caso el prisionero conserva la diadema de Ahau, seguramente para indicar el rango de gobernante del mismo; se trata de Kan Hok Chitam (II) de Palenque (fig. 3).

Por estas observaciones fue posible reducir a un número más real la cantidad de prisioneros pues, como he dicho, el mismo puede estar representado varias veces, $y$ es conveniente señalar este punto que no había sido considerado en el estudio acerca del propósito que se perseguía al hacer la guerra.

Sabemos por la información de otros sitios, que los gobernantes usaban entre sus títulos el de "captor de . ..", y después mencionaban el nombre de su cautivo favorito. Y la observación va en ese sentido ¿por qué ese cautivo? Tomemos como caso la captura de Kan Hok Chitam (II), llevada a cabo por el gobernante 3 de Toniná, Baknal-Chak. Desde un punto de vista occidental, dicha captura debía estar mencionada varias veces y el triunfo sobre esa gran ciudad, Palenque, debió haber contribuído económicamente en beneficio de la otra. Pero no es el caso en Toniná y posiblemente tampoco lo fue en otras ciudades mayas.

Tomemos como otro ejemplo el caso de Yaxchilán. No sabemos quiénes fueron Cráneo Enjoyado, o Ah

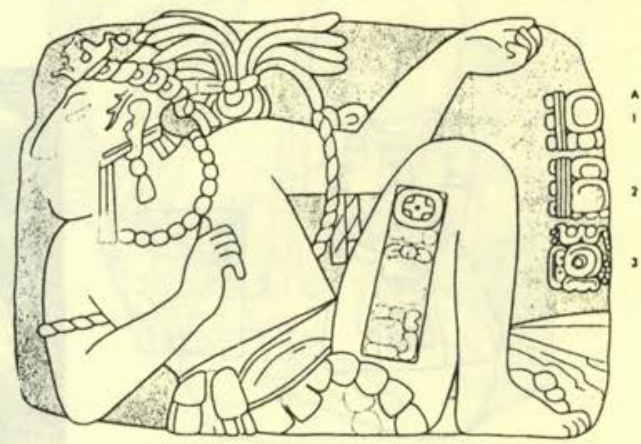

Fig. 3. Captura de Kan Hok Chitam (II) de Palenque (dibujo de Mathews). 
Entre los recientes desciframientos e identificaciones epigráficas asociadas al tema de la guerra se encuentran varios compuestos. De entre ellos, solamente el llamado "estrella-concha" está escrito en Toniná. En el primer caso se refiere a la guerra contra Kan Hok Chitam (II) (fig. 3), y en el otro no sabemos contra quién fue pues el resto del texto está perdido, pero ello no significa que Toniná no participó en batallas, pues como se ha dicho, se conservan varias imágenes de prisioneros en el sitio.
El compuesto glífico asociado a la guerra más abundante en Toniná es el de "captura", kuch. Por él sabemos que fue el gobernante 2, Balam-Way, quien inició tal práctica, así como la de los sacrificios posteriores a la captura. En el M.8 (fig. 8) se conmemora un final de periodo, 9.12.10.0.0, 9 Ahaw 18 Zotz, y están representados tres prisioneros pero no tenemos sus nombres ni su procedencia. La fecha, por su propia naturaleza calendárica, está repetida en muchos sitios, pero no es
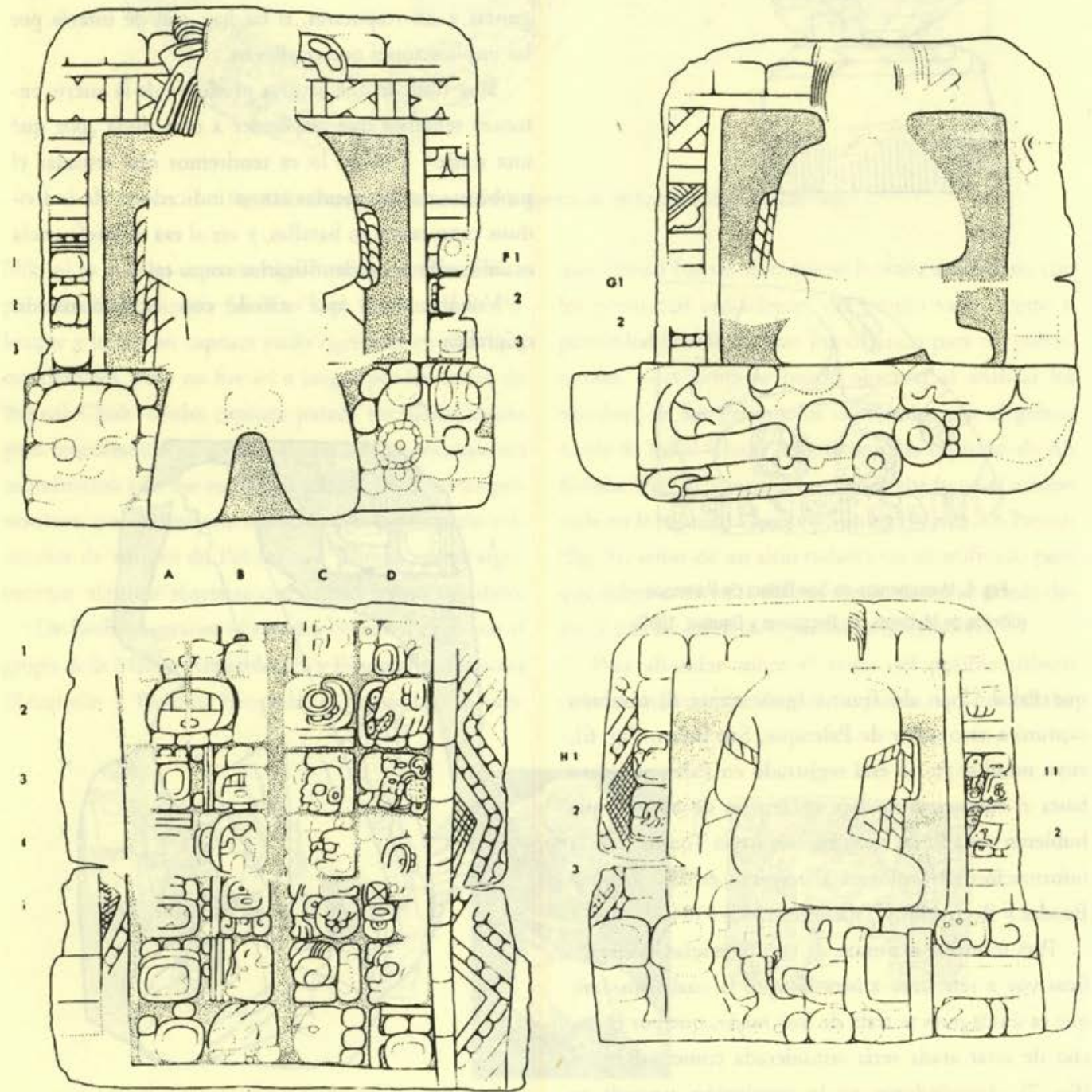

Estudios de Cultura Maya. Vol. XXII, 2902 . Monumento 8 (dibujo de Mathews). 

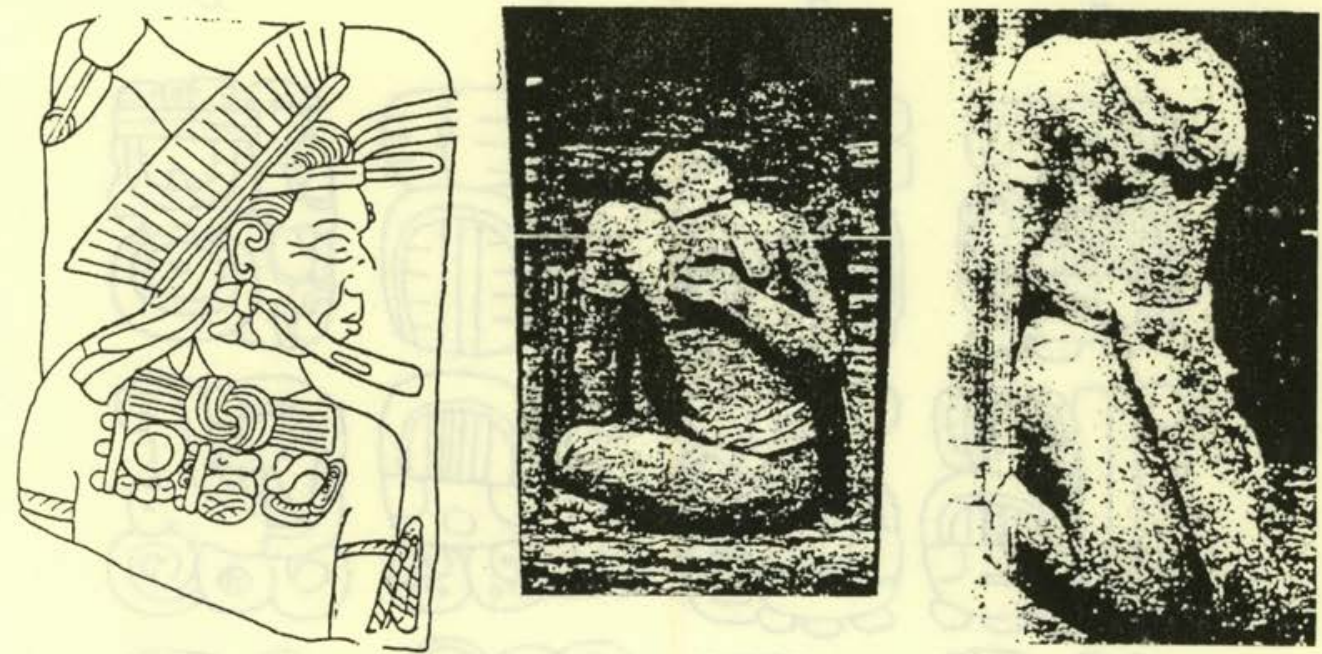

Fig. 9. Prisionero usando el mismo collar y representado en diferentes monumentos (Ayala, 1995).

posible deducir a través de ella contra quién fue la posible batalla.

El gobernante 3, Baknal-Chak, fue entronizado en 9.12.16.3.12, 5 Eb $20 \mathrm{Xul}$ (19 de junio de 688) y a juzgar por sus obras escultóricas y arquitectónicas, todo indica que fue un personaje con gran poder. Cómo lo obtuvo es difícil saberlo, aunque mi opinión, si la identificación que hice de la procedencia de los jades Squier y su tumba son correctas, es que se apoyó en una relación con Dos Pilas. Lo que sí podemos anotar con certeza es que su primera captura está anotada en el M.A1 ${ }^{4}, 9 \cdot 13 \cdot 0.0 .01$ Ahaw 3 Pop, final de periodo asociado por un número distancia a la fecha (9.13.0.10.13) 3 Akbal $11 \mathrm{~K}$ 'eh, cuando capturó y se comió, o torturó, kuxah, a un personaje llamado Kuk'(u)-ahau-che. La misma fecha con el verbo de captura está en un fragmento de hueso. El registro de la fecha del katun 13 también se encuentra en los M.134 y M.140.

Su siguiente captura, llevada a cabo en 9.13.19.13.3, 13 Akbal 16 Yax (30 de agosto de 711), fue la de Kan
Hok Chitam (II) de Palenque y de quien, como ya se dijo, sólo se conoce una inscripción atestiguando el hecho (M.122) (fig. 3). Frente al edificio E5-5, el del "dintel de madera", se localizó un disco erosionado, con fecha en rueda de calendario y que puede corresponder a 9.13.12.3.14, 8 Ix 7 Zip, o a 9.13.0.13.4 8 Kan 7 Zip. Cualquiera que sea la fecha, ambas caen en el gobierno de Baknal-Chak. Lo importante es el collar del prisionero, pues el mismo personaje está representado en otras dos ocasiones (fig. 9). Por desgracia tampoco tenemos su nombre, pero debió ser alguien relevante pues mereció más monumentos que Kan Hok Chitam.

Tiempo después, en 9.14.3.8.4 2 Kan 17 Sotz' ( 2 de mayo de 715), sin que sepamos cuál fue la causa, Baknal-Chak impuso un gobernante en Bonampak (fig. 10). Ah Aknal-Chak le corresponde otro cautivo registrado en el M.27, quien lleva una corta inscripción en ambos lados de su imagen, que se lee: K'awil/ mo-hy ye-t / Baknal-Chak.

El prisionero lleva su nombre en la pierna: Choo? chak-bi-l(i), pero no hay mayor información respecto

\footnotetext{
${ }^{4}$ Los monumentos anotados como M.A\# fueron descubiertos por el grupo de arqueólogos mexicanos, pero no han sido catalogados. Por ello los numeré con un orden progresivo conforme a sus fechas. La mayoría de estos monumentos no han sido publicados o lo están sólo parcialmente.
} 


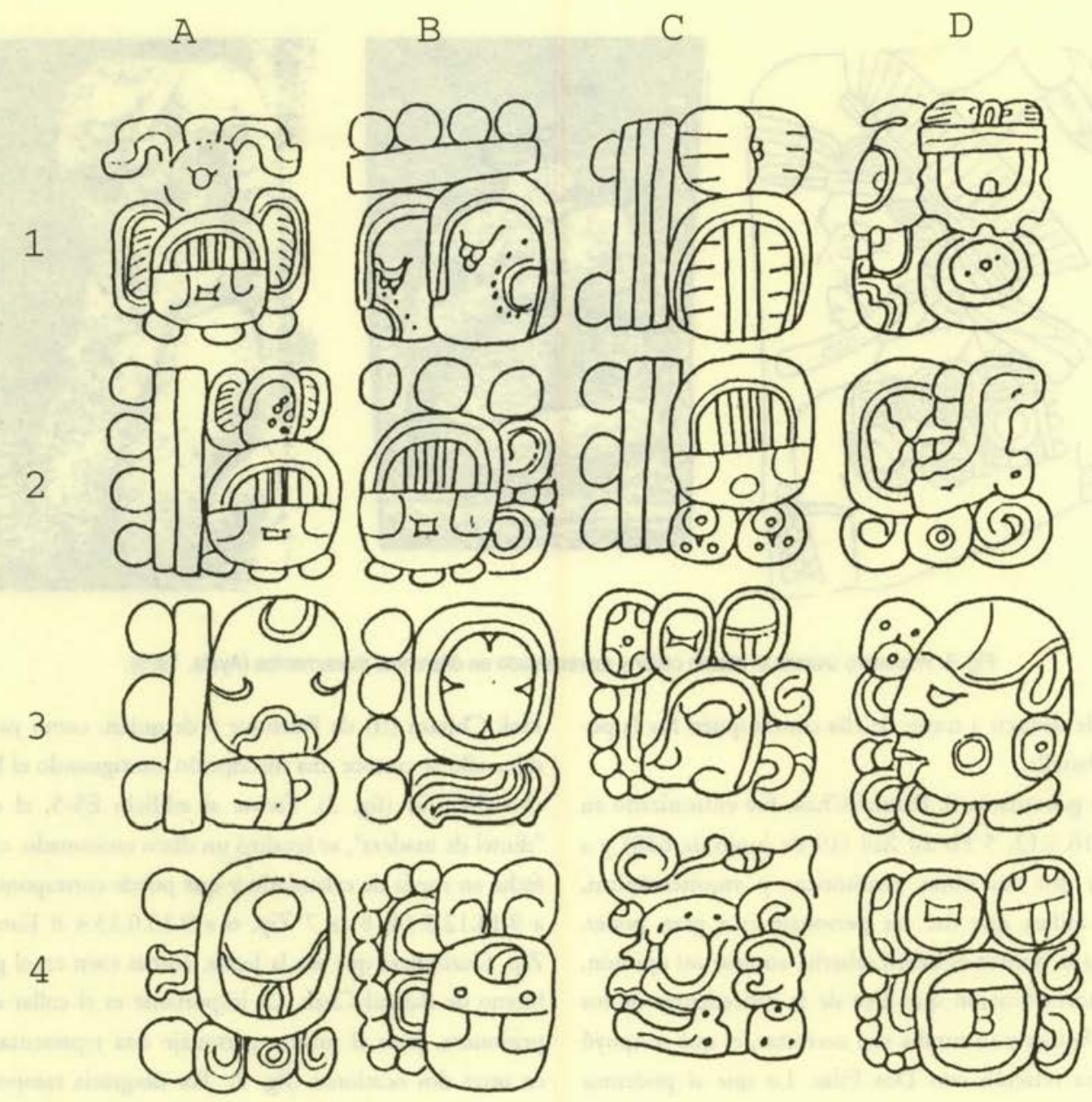

Fig. 10. Estela de San Louis (dibujo de Schele).

a él. Ni siquiera por el collar se le ha podido identificar con otros prisioneros correspondientes a este gobernante, pero sí con algunos del gobernante 8 .

No sabemos cuándo murió, pero fue antes de 9.14.15.10.9 12 Muluk 2 Sotz (14 de abril de 727), fecha en que se entronizó el siguiente gobernante; pero antes de terminar con sus actividades bélicas quiero volver a referirme a la mención de su posible alianza con Dos Pilas.

Ésta se apoya en un jade de la colección Squier, mismo que fue comprado en Ocosingo y que, según el Estudios de Cultura Maya. Vol. XXII, 2002 mismo Squier, estaba dentro de un vaso que sólo tenía "fragmentos de huesos cremados", el cual fue localizado dentro de una tumba abovedada. El jade que nos interesa tiene una inscripción (fig. 11) donde se menciona a Balah Kan K'awil, (de Dos Pilas) como señor de 4 katunes. Por las fechas de este gobernante y los de Toniná, el único personaje que pudo haber recibido como obsequio tal joya era Baknal-Chak, y seguramente la relación entre ambos fue tan importante que lo enterraron con el jade. Para apoyar mi hipótesis voy a referirme a un nuevo disco de Toniná, el M.A6, 

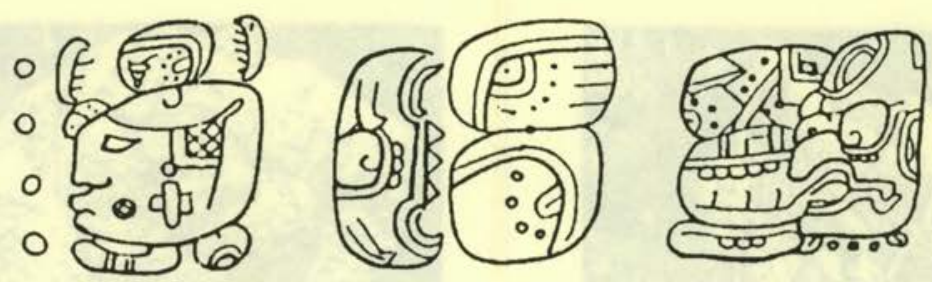

Fig. 11. Jade procedente de la tumba de Baknal Chak (tomado de Easby, 1961).

donde se registra la incineración de los restos de Baknal-Chak en 9.14.18.14.12 5 Eb 19 Yaxk'in (20 de junio de 730), fecha aniversario de su entronización y de una importante alineación astronómica.

Los siguientes gobernantes se sucedieron rápidamente; tres fueron hombres: Ox-Kan, que duró un poco más que los otros dos; Ak-Motz, de quien sólo hay un monumento, y "Zotz-Choj", de quien también solamente tenemos una inscripción.

Mi identificación del gobernante 7 está sujeta a críticas, pero no estoy de acuerdo con el identificado por Mathews como tal pues ese personaje murió antes de acceder al trono. Todo parece indicar que fue el hijo mayor de Na K'awil, a quien identifico como la 7a gobernante del sitio (M.A 8) (fig. 12). Aunque su inscripción es un monumento póstumo, igual que el de su hijo, ambos debieron ser hechos por su otro hijo, el gobernante 8 , quien además de ser artista era guerrero $y$ que, en uno de sus monumentos señala muy claramente haber sido hijo de $\mathrm{Na}$ K'awil, siendo éste el único relacionador de parentesco en el sitio.

Antes de tratar al gobernante 8 quiero mencionar otro monumento. Se trata de uno de los tres tronos ubicados en la quinta terraza - frente a un gran mural de estuco-- y el cual lleva en la espalda una inscripción que se refiere a otra mujer, $\mathrm{Na} \mathrm{Nal}$-pi, o $\mathrm{Na}$ Pi-nal. La razón para referirme a ella es porque debajo de su nombre, dentro de un nicho, está un prisionero a quien identifiqué por su procedencia glífica y por el collar, que porta en tres monumentos más (fig. 13). El prisionero procede de Anayté, sitio cercano a Yaxchilán. Cabe señalar que a un lado del trono se encuentra una caja de estuco, aún cerrada y decorada con otro caurivo.

El mural de estuco ubicado en el talud detrás de los tronos está incompleto. Falta la primera parte donde seguramente estaba la captura de un personaje que fue decapitado, pero desconocemos al autor de tal evento. Lo que sí sabemos es su procedencia; venía de Pi-a, ${ }^{5}$ sitio cercano a Pomoná. En este caso me interesaba señalar la relación entre el trono de la señora, sus cautivos y su ubicación frente al gran mural, aunque es cierto que no sabemos quién fue ella y si pudo tener alguna relación con $\mathrm{Na}$ K'awil.

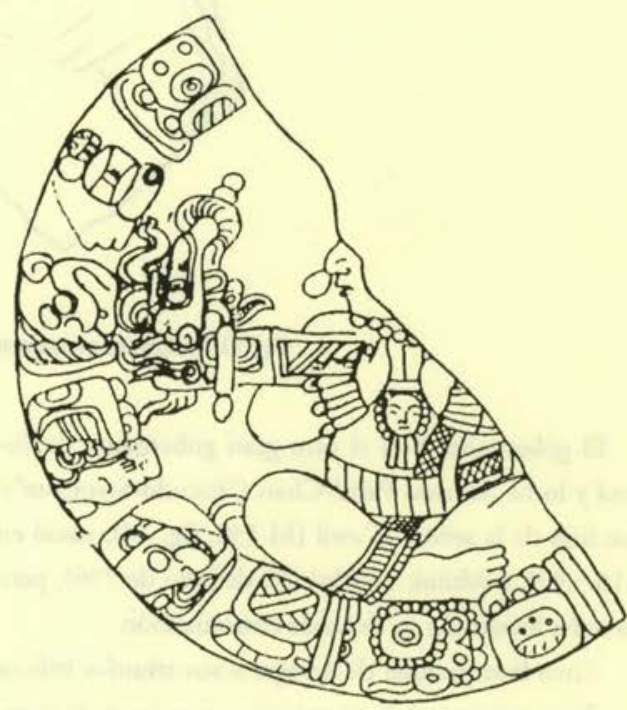

Fig. 12. Disco de la Sra. Kawil (dibujo de Ayala).

${ }^{5}$ La lectura e identificación del sitio es de Grube y Schele (comunicación personal, marzo de 1993).

Estudios de Cultura Maya. Vol. XXII, 2002

Instituto de Investigaciones Filológicas/ 

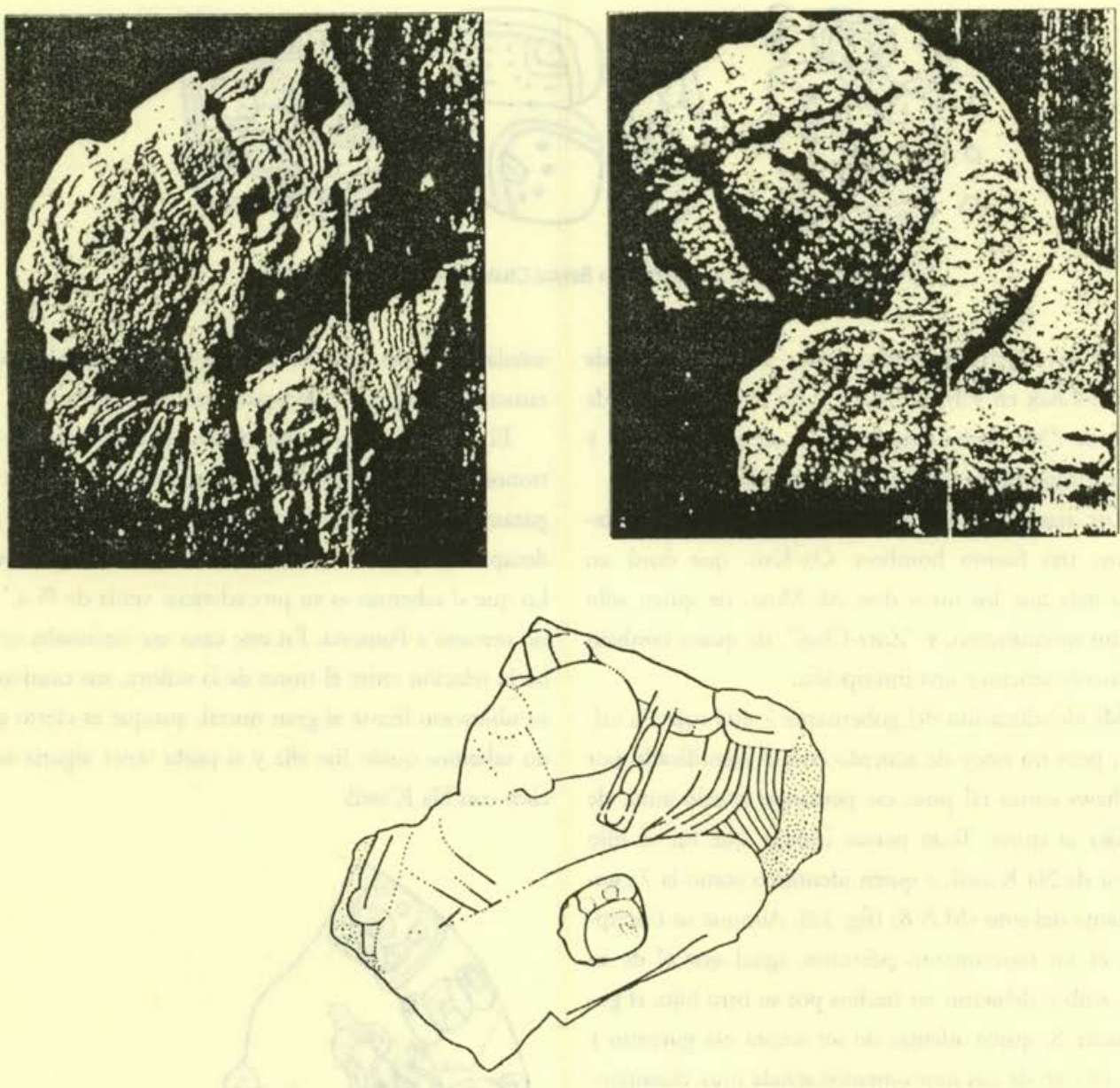

Fig. 13. Prisioneros procedentes de Anayté (dibujos de Mathews).

El gobernante 8 es el otro gran gobernante de Toniná y lo he llamado Pakal-Chan ("Escudo-Serpiente"). Fue hijo de la señora K'awil (M.138, fig. 14), nació en 9.16.5.4.9, 6 Muluk $17 \mathrm{Mol}$ ( 10 de julio de 756), pero no se ha localizado su fecha de entronización.

Tuvo la capacidad de agregar a sus triunfos bélicos sus obras artísticas y arquitectónicas, pero jamás se autorepresentó como guerrero. La información que voy a presentar sobre las identificaciones de sus prisioneros procede de los datos recabados en los documentos históricos, combinados con la iconografía y la epigrafía. Estudios de Cultura Maya. Vol. XXII, 2002
Hasta el momento todo parece indicar que su primera captura fue la de alguien de Poyom, como puede apreciarse en el M.A 11 (fig. 15), y en los M.108, M.74, M.41 (fig. 16), y otro más sin nomenclatura. La captura se llevó a cabo en 9.17.18.3.9, 2 Muluk 12 Ch'en (17 de julio de 789).

El sitio está incluído en la región territorial que le fue concedida a Pedro de Alvarado por la Corona española, aunque él la llamó Poyomatlán. A pesar de la información no sabemos dónde estaba y supongo que, posiblemente, antes se llamó de otra forma. Mi su- 


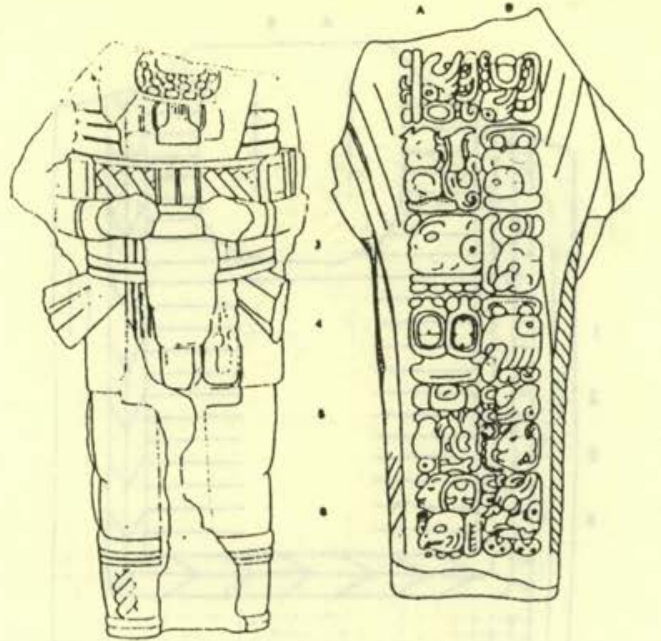

Fig. 14. Monumento 138 (dibujo de Keetz, en Becquelin y Taladoire).

puesto se apoya en el hecho de que los poyom usan el mismo collar que lleva el prisionero del M.27, capturado por Baknal-Chak.

Pakal-Chan, además de reformar el juego de pelota hundido y colocar en el agujero del centro el disco conmemorativo de la muerte de su hermano, cambió los "marcadores", sustituyéndolos por otros horizontales formados por esculturas de cautivos, en bulto, apoyadas sobre representaciones de escudos flexibles que llevan en el borde superior las piernas del cautivo, en cuclillas, $y$ en el resto del escudo iba una inscripción que mencionaba su nombre (fig. 17).

De los cuatro textos sólo en dos se puede identificar a los sujetos. Ambos están representados, además, en otras imágenes de cautivos. Todos debieron ser importantes, pero para nuestro propósito el que está en el M.65 es de gran interés. Se trata de Sak-Balam de Palenque, quien también está registrado en los M.107, F.43, posiblemente en el F.1 (fig. 6), y en otro no clasificado ni publicado. Sak-Balam no está mencionado en Palenque, pero no hay duda de su procedencia y nos es de interés por ser una evidencia más de la enemistad que existió entre ambas ciudades a lo largo de sus historias. El otro individuo se llamaba 4-Ma-s y está representado también el M.84.
Después de las capturas mencionadas, Pakal Chan se dirigió contra el vecino de enfrente, Ah Kololte, como consta en los M.A12 y F.82 (fig. 4), y que pudo ocupar la montaña de enfrente en el mismo valle donde el nombre aún se conserva. Kololte murió, y fue taladrado hoch, en 9.18.5.10.3, 12 Akbal 11 Sotz' (5 de abril de 796).

Existen otras dos inscripciones, M.130 y M.131 (fig. 18), con la representación del mismo individuo. No sabemos la fecha en la que fue capturado, y su
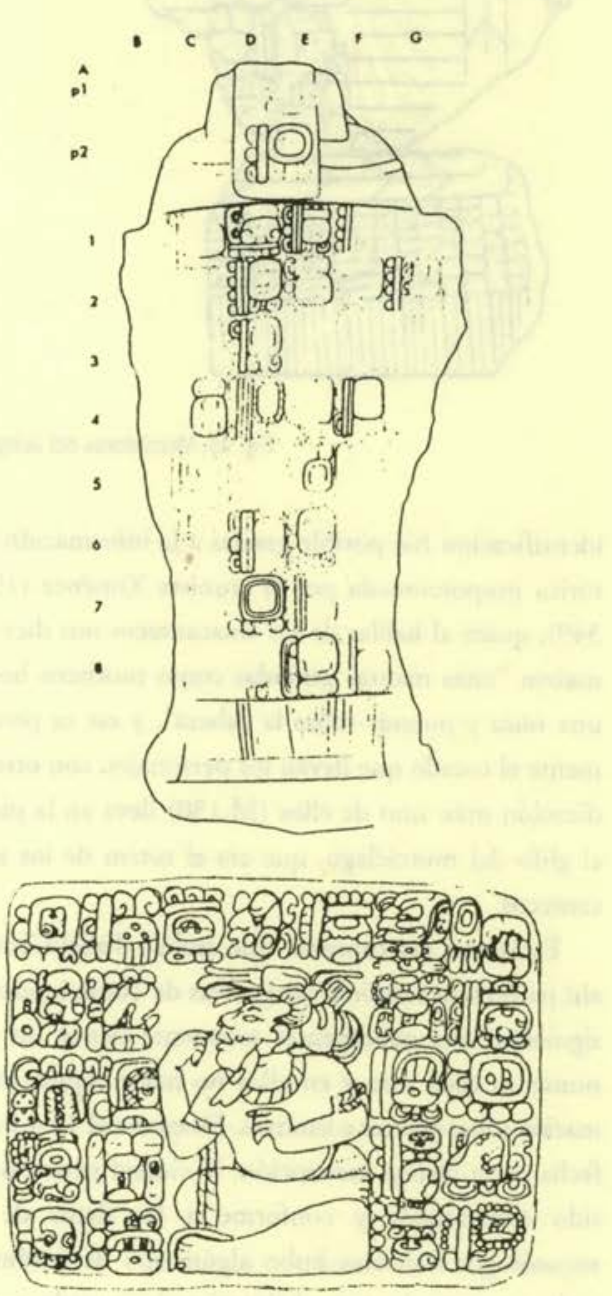

Fig. 15. Monumento 20 y Monumento A11 (dibujos de Mathews y Ayala). 



Fig. 16. Marcadores del Juego de pelota (en Becquelin y Baudez, 1982).

identificación fue posible gracias a la información histórica proporcionada por el cronista Ximénez (1965: 349), quien al hablar de los zinacantecos nos dice que usaban "unas mantas pintadas como moriscos hechas una rosca y puestas sobre la cabeza", y ese es precisamente el tocado que llevan los personajes, con otra indicación más: uno de ellos (M.130) lleva en la pierna el glifo del murciélago, que era el totem de los zinacantecos.

Estas son las capturas que realizó Pakal-Chan, y ahí parecerian terminar las guerras de Toniná, pues los siguientes tres gobernantes solamente tienen un monumento cada uno y en ellos no hay ninguna información sobre guerras o cautivos. Después del 10.4.0.0.0, fecha de la última inscripción, la ciudad parece haber sido abandonada y conforme a los datos de los arqueólogos franceses hubo algún tipo de fenómeno violento, pues la zona habitacional ocupada por la élite fue quemada. El sitio quedó abandonado por un tiempo y después lo volvieron a habitar, reocupando y Estudios de Cultura Maya. Vol. XXII, 2002

Instituto de Investigaciones Filológicas/

Centro de Estudios Mayas, UNAM

ISSN 0185-2574 renovando la zona habitacional y recolocando el M.131 "enmedio de la escalinata". La pregunta que surge es ¿̨por qué el monumento que habla de la captura de los zinacantecos? Tiempo después abandonaron la montańa y se bajaron a ocupar el valle, donde permanecieron hasta la llegada de los espan̄oles, contra quienes enfrentarían nuevas batallas.

Hasta aquí las evidencias epigráficas, iconográficas $\mathrm{y}$ arqueológicas accesibles a nosotros, demuestran que las manifestaciones culturales del sitio corresponden sin duda al ámbito maya, y que al mismo tiempo se comporta de una manera independiente. $\mathrm{Si}$ nuestro trabajo se hubiera centrado sobre uno solo de los aspectos culturales a los que aludimos, posiblemente tendríamos la duda acerca de las guerras entre Toniná y otras entidades políticas. Después de todo los gobernantes no se muestran con atuendo de guerreros y solamente se conocen dos representaciones de glifos para guerra. Hasta el momento el Glifo Emblema de Toniná no está registrado en ningún otro sitio, lo cual 

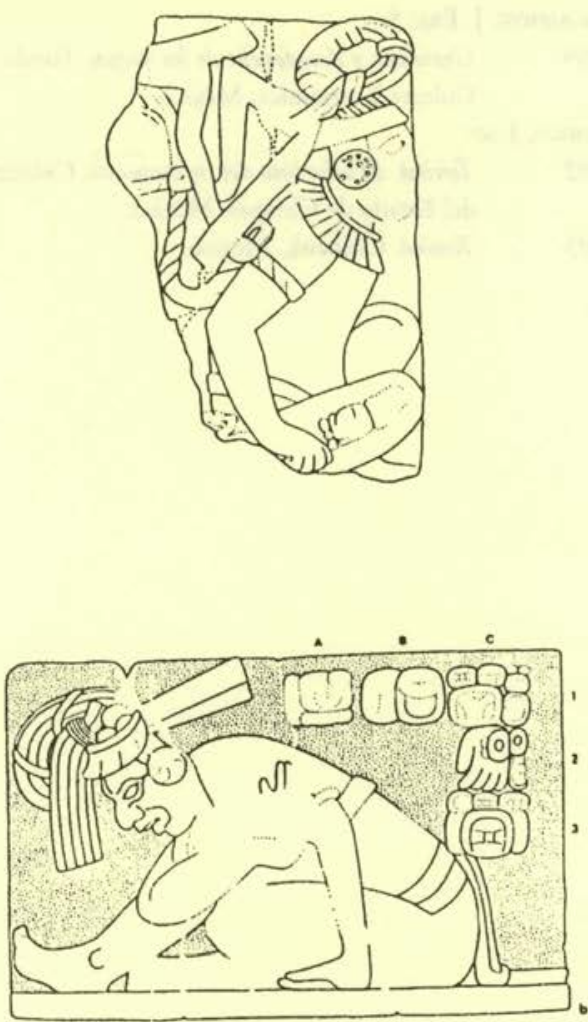

Fig. 17. Monumento 130 y Monumento 131, con los prisioneros zinacantecos (en Becquelin y Taladoire, 1990).

implicaría que nunca fueron derrotados, sin embargo no hay evidencias arqueológicas o epigráficas de alguna clase de tributo; entonces tendríamos que preguntarnos: ¡cuál era la ganancia de tales batallas? ¿Sólo el prestigio del gobernante o la independencia del valle?

Como puede observarse la historia de los Póo winik’ob no terminó con el colapso maya, así como tampoco sus luchas por conservar su propio habitat: el valle.

Si durante el Clásico se valieron del grupo al que pertenecían Caracol y Dos Pilas, al inicio de la colonización española se aliaron con los lacandones, y las entradas a los nuevos asentamientos españoles por parte de los lacandones y los pochutlas, que es como llamaron a los Pó winikiob, están ampliamente relatadas en las crónicas coloniales que se refieren a la zona de la Vera Paz, que tenía y tiene de todo, menos paz.

\section{Bibliografia}

\section{ayala F, Marucela}

1995 The history of Tonina through its inscriptions. Ph. D. dissertation, U. de Texas en Austin

s.f. "Acerca de las mujeres y la sangre sagrada: los Glifos Emblema"; Ms. en propiedad de la autora.

Baudez y Peter Mathews

1978 "Capture and Sacrifice at Palenque", en Tercera Mesa Redonda de Palenque, vol. IV: 31-40. Pre-Columbian Art Research Center, Chiapas, México.

Becquelin, Pierre y Claude Baudez

1982-1984 Tonina. Une cité maya du Chiapas (Mexique), Estudios Mesoamericanos, vol. VI, 3 tomos, Centro de Estudios Mexicanos y Centroamericanos, México.

Becquelin, Pierre y Eric Taladoire

1990

Tonina. Une cité maya du Chiapas (Mexique), Estudios Mesoamericanos, vol. Vl, tomo 4. Centro de Estudios Mexicanos y Centroamericanos, México.

EAsBy, El.IZABETH

1961 "The Squier Jades From Toniná, Chiapas", en Essays in Pre-Columbian art and archaeology. pp. 60-80. Harvard University Press, Cambridge, Massachussets.

Gelb, I. J.

1963 A study of writing. The University of Chicago Press, Chicago.

Maudstay, Al.fred Percival.

1889-1902 Biologia Centralli-Americana, 5 v, Dulane and Company, Londres.

Marcus, JoYce

1976 Emblem and State in the Classic Maya Lowlands. An Epigrahic Approach to Territorial Organization. Dumbarton Oaks, Trustees for Harvard University, Washington, D.C.

Mathews, Peter

1983 Tonina. Corpus of Maya Hieroglyphic Inscriptions. Volumen 6, parte 1. Peabody Museum of Archaeology and Ethnology, Harvard University, Cambridge, Massachussets.

SCHELE, Linda y Mary MiLIER

1986 The Blood of Kings. Dinasty and Ritual in Maya Art. Kimbell Art Museum, Fort Worth, Texas.

SCHElE, Linda y DAVId Freidel.

1990 A Forest of Kings. The Untold Story of Ancient

Estudios de Cultura Maya. Vol. XXII, 2002

Instituto de Investigaciones Filológicas/

Centro de Estudios Mayas, UNAM 
Maya. William Morrow and Company Inc., New York.

Smallus, OrTWIN

1975 El Maya-Chontal de Acalan: Análisis lingüistico de un documento de los años 1610-1612. Cuaderno No. 9, Centro de Estudios Mayas, UNAM, México.
THOMPSON, J. ERIC S.

1959 Grandeza y decadencia de los mayas. Fondo de Cultura Económica, México.

YADEUN, JUAN

1992 Tonina. El laberinto del inframundo. Gobierno del Estado de Chiapas, México.

1993 Toniná. Citibank, México. 